\title{
Sermaye Şirketlerinde Sermaye Artırım İşlemleri ve Muhasebeleştirilmesi
}

\author{
Nuraydın TOPÇU* \\ Vedat DEMIRKOL ${ }^{* *}$
}

\section{ÖZET}

İsletmelerde kârın tamamının dağıtılmayıp bir kısmının işletmede bırakılmasının, işletmelerin sermaye yapılarının iyi durumda olmasının ve yetkili otoritelerce alınan tedbirlerin ne derece önemli olduğu; 2008 yılında Amerika'da başlayan ekonomik krizin tüm Dünyayı etkilemesiyle daha da iyi anlaşılmıştır. Yine ekonomik kriz, tamamen borca dayalı büyüme modelinin ne firmalar, ne de dünya için geçerli bir yöntem olmadiğını yatırımcılara ve ülkelere acı bir biçimde göstermiştir.

Bu yüzden işletmeler sermaye yapılarını güçlendirmek ve sermaye oranlarını daha iyi duruma getirmek için iç ve dış kaynaklardan sermaye artırım yoluna gitmek zorundadırlar. Işletmeler ister iç kaynaklardan ister dış kaynaklardan sermaye artırım yoluna gitmek istesinler, tabi oldukları mevzuata göre belirli kanuni yükümlülükleri yerine getirmek zorundadırlar. Sermaye artırım işlemlerinde mevzuatlarda farklı düzenlemelerin olması, muhasebe sonuçlarının da farklı olmasına neden olmaktadır. Bu çalışmanın amacı, Türkiye'de muhasebe uygulamalarına yön veren, Türkiye Muhasebe Standartları (TMS), 6102 Sayll Türk Ticaret Kanunu (TTK), 5520 Sayll Kurumlar Vergisi Kanunu (KVK) ve 213 Sayılı Vergi Usul Kanunu'nda (VUK) yer alan sermaye artırım hükümleri ve sermaye artırım işlemlerini incelemek ve muhasebeleştirme sürecini ele almaktır.

Anahtar Kelimeler: Sermaye, Sermaye Artırma, Sermaye Artırım Maliyetleri.

\section{Accounting Of Capital Increment Transactions In Capital Companies}

\section{ABSTRACT}

2008 global financial crisis revealed that how the dividend policy and capital structure decisions for companies is important and the growth models based on debt caused the difficulties. Because of that companies have to increase their capital and strengthen their capital structure. Existence of different arrangements in legislation for capital increase transactions causes the accounting results to differ. In this study, capital increase provisions and process of recognition which are ranked on Turkish Accounting Standards (TAS), Turkish Commercial Code (TCC) and Tax Procedure Law (TPL), Corporate Tax Law (CTL) have been analyzed.

Keywords: Capital, Capital Increasing, Capital Increasing Cost.

Jel Classification: M41, M49.

\footnotetext{
* Yrd. Doç Dr. Nuraydın Topçu, Yalova Üniversitesi, İktisadi ve İdari Bilimler Fakültesi, nuraydin.topcu@yalova.edu.tr

** Arş. Grv. Vedat Demirkol, Yalova Üniversitesi, İktisadi ve İdari Bilimler Fakültesi, vdemirkol@yalova.edu.tr
} 


\section{GíRiş}

Finansal tablolar, işletmelerin faaliyet sonuçları, finansal durumları ve durumundaki değişiklikler hakkında finansal bilgi kullanıcılarına bilgiler sunan en önemli kaynaklardır. Bu kapsamda, işletme yönetimlerinin yeterliliğini ve işletmelerin hesaplarını gözden geçirmek isteyen kullanıcılar, finansal tablolara dayanarak ekonomik kararlar vermekte ve işletmelerin faaliyetlerini bu tablolara göre değerlemektedirler. Dolayısıyla, finansal tablolarda yer alacak bilgilerin nitelikleri ve doğrulukları finansal tablo kullanıcıları için büyük önem arz etmektedir.

Çalışmada, 6102 sayılı Türk Ticaret Kanunu’nun sermaye artırımı ile ilgili getirmiş olduğu yenilikler ve Türkiye'deki diğer mevzuatta yer alan sermaye artırım işlemleri ve muhasebeleştirilme konusu ele alınacaktır

\section{SERMAYE KAVRAMI}

Sermaye kavramı, ekonomi, hukuk ve muhasebe bilimleri bakımından farklı anlamlar taşımaktadır. Ekonomi biliminde sermaye, emeğin verimliliğini artıran ve önceden üretilmiş olan üretim araçlarıdır (Parasız, 2007: 512). Hukukî açıdan sermaye, bir ticarî işletmenin ya da ortaklığın amacına ulaşması için söz konusu işletme ya da ortaklığa tahsis edilen maddi ya da gayri maddi malvarlığı unsurları ile parayla ölçülebilen değerlerin tümüdür ( İnal, 2003: 854).Muhasebe bilimi açısından ise sermaye, "esas sermaye” ve "öz sermaye” olarak iki farklı kavram olarak ele alınmakta olup, esas sermaye bir işe tahsis olunan paranın ya da parayla ölçülebilen değerlerin toplamını ifade ederken, özkaynak ise daha geniş bir kavram olup, işletme sahibinin işletmeye yaptığı yatırımların toplamını ifade etmektedir (Collin, 2007: 84).

\subsection{Sermayenin Artırılması}

İşletmelerin yaşamlarını sürdürebilmeleri için güçlü bir sermayeye sahip olmaları ve sahip oldukları mevcut sermayenin fiziki ve nominal olarak daha da güçlü kılmalarına bağlıdır. Bu sebeple işletmeler dört tür amaçla sermaye artırma yoluna gitmektedirler. Bunlar (Yavuz, 2011);

1- Mevcut sermaye yapılarını güçlü kılmak,

2- Artan iş hacmini karşılamak,

3- Yasal sermaye tabanını karşılamak,

4- benzeri fonları sermayeye dönüştürmek,

Sermaye artırımı, esas sözleşme değişikliğinin özel bir türünü teşkil etmektedir. Dolayısıyla, şirket sermayesinin artırılması belli usullere tabidir. Bu kapsamda, 6102 Sayılı Türk Ticaret Kanunu’nda üç çeşit sermaye artırım yöntemi öngörmektedir. Bunlar; bedelsiz sermaye artırımı, bedelli sermaye artırımı ve şarta bağlı sermaye artımıdır (TTK 459-462). 
Bedelsiz sermaye artırımı, şirketlerin kendi iç kaynaklarını (emisyon primi, yeniden değerleme artışı, yedekler, iştirak ve duran varlık satış kârları, temettü) kullanarak yapmış oldukları sermaye artırım yöntemidir. Bu yöntemde, ortaklarından ilave kaynak talep edilmeksizin, bedelsiz olarak ortaklara hisse senedi dağıtımı yapılmaktadır.

Bedelli sermaye artırımı, şirketlerin dış kaynaklardan temin etmiş oldukları yeni kaynaklar karşılığında sermaye artırmak suretiyle hisse senedi çıkartma yöntemidir. Ortakların bedelli sermaye artırımına katılma hakları da "Rüçhan Hakkı" olarak adlandırılmaktadır.

Şarta bağlı sermaye artırımı, yeni çıkarılacak tahvillerin ve benzeri borçlanma araçlarının alacaklılarının şirketin pay sahiplerine dönüşmelerini amaçlayan ve bu yolla şirkete sermaye sağlayan ve çalışanlar için pay senedi çıkarılmasına olanak veren bir sermaye artırım yöntemidir.

\subsection{Esas Sermayenin Artırılması Prosedürü}

6102 Sayılı TTK'da sermaye artırımına yönelik olarak esas sermaye (TTK md.453) ve kayıtlı sermaye sistemleri getirilmiştir (TTK md. 456). Esas sermaye sisteminde sermaye artırımına genel kurul, kayıtlı sermaye sisteminde ise sermaye artırımına yönetim kurulu karar vermektedir. TTK, sermaye şirketlerinin sermaye artırımı yapabilmesi için bazı hususları yerine getirmesini şart koşmuştur (Şengür, 2011;105). Bu koşullar TTK'nın 456. ve 457. maddelerinde düzenlenmiştir. TTK'nın 456. maddesine göre, işletmelerin iç kaynaklardan yaptıkları sermaye artırımı hariç olmak üzere, hisselerin nakdi bedelleri tamamen ödenmediği sürece işletmeler sermaye artırımı yapamamaktadırlar. Yani, öncelikle ödenmemiş sermayenin ödenmesi gereklidir. Öte yandan, sermayeye oranla önemli sayılmayan tutarların ödenmemiş olması sermaye artırımına engel olmaz (Yavuz, 2011). TTK'nın 457. maddesinde, sermaye artırımı yapabilmek için öncelikle, yönetim kurulunun sermaye artırımı ile ilgili bir beyan hazırlayıp, bunu imzalama yükümlülüğü bulunmaktadır. Buna göre, yönetim kurulu tarafindan hazırlanan beyanda aşağıdaki hususların yer alması zorunludur:

- Sermaye artırımında nakdi sermaye konuluyorsa; artırılan kısmın tamamen taahhüt edildiği veya ödenmesi gereken tutarın ödendiğii,

- Ayni sermaye konuluyor ve bir ayın devralınıyorsa bunlara verilecek karşılığın uygun olduğu,

- Bir borcun takası söz konusu ise; bu borcun varlığı, geçerliliği ve takas edilebilirliği,

- Sermayeye dönüştürülen fonun veya yedek akçenin serbestçe tasarruf olunabilirliği,

- Rüçhan hakları sınırlandırılmış veya kaldırılmışsa bunun sebepleri, miktarı ve oranı, kullanılmayan rüçhan haklarının kimlere, niçin, ne fiyatla verildiği hakkında açıklamalar raporda yer almalıdır.

- Sermaye artırımı, iç kaynaklardan sermaye artırımı şeklinde gerçekleşmekte ise, yönetim kurulu beyanında ayrıca iç kaynaklardan yapılan sermaye artırımının hangi 
kaynaklardan karşılandığı, bu kaynakların gerçekliği ve şirket malvarlığı içinde var oldukları konusunda garanti vermelidir. Şartlı sermaye artırımının söz konusu olduğu durumlarda ise, şartlı sermaye artırımının ve uygulamasının kanuna uygunluğu belirtilmelidir.

\section{SERMAYE ARTIRIM IŞLEMLERININ MUHASEBELEŞTIRILMESINE YÖNELIK YAPILAN YASAL DÜZENLEMELER}

Türkiye'de sermayenin artırılmasına yönelik; Türk Ticaret Kanunu, Muhasebe Standartları, Sermaye Piyasası Kanunu, Vergi Usul Kanunu ve Muhasebe Uygulama Genel Tebliğinde bazı düzenlemeler yapılmıştır.

\subsection{Türk Ticaret Kanunu’ndaki İlgili Düzenleme}

6102 Sayılı Türk Ticaret Kanunu’nun büyük bir kısmı Alman Ticaret Kanunu’nun (ATK) birebir çevirisidir. Nitekim sağlanmasına ilişkin oluşan işlem maliyetleri hakkında olan ATK'nın 248. maddesi, TTK’ya alınmıştır. ATK'dan alınan hüküm TTK'nın 74. maddesinin birinci fikrasında düzenlenmiştir. Söz konusu TTK hükmünde "Türkiye Muhasebe Standartlarında aksi öngörülmemişse, işletmenin kuruluşu ve sağlanması amacıyla yapılan harcamalar için bilançoya aktif kalem konulamaz.” denilmektedir. Bu hüküm gereğince işletmenin kuruluşu ve özkaynağın sağlanması amacıyla yapılan harcamalar için bilançoya aktif kalem konulamayacak ve yapılan harcamalar sonuç hesaplarına aktarılmak suretiyle giderleştirilecektir. Aynı kanunun gerekçesinde de, kuruluş ve örgütlenme giderleri için yapılan bilirkişi, kuruluş denetçisi, noter, avukat ücretleri, tescil giderleri ve çeşitli vergi ödemeleri sonucunda işletmeye herhangi bir varlık girişi sağlamaması nedeniyle, sonuç hesaplarına aktarılmasını öngörmektedir. Öyle ki, sağlanabilmesi için yapılan ihraç, izahname, pay senedi basım ve aracı kurum komisyon giderleri işletmeye herhangi bir varlık girişi sağlamadığından, anılan giderlerin maddi olmayan duran varlık olarak sınıflandırılmayarak, sonuç hesaplarına aktarılması öngörmektedir.

Maddi olmayan duran varlıklar ATK'na göre; iktisadi bir kıymetin varlığı, bağımsız bir şekilde değerlendirilebilirlik, kavranabilirlik, bir iktisadi yılı aşacak surette iktisadi yarar sunma, bağımsız bir şekilde tasarruf etme, harcamanın varlığı, tek başına ticari ilişkiye konu olabilme özelliğinin (bağımsız bir şekilde devredilebilirlik) bulunması gereklidir (Başaran, 1999: 68-73). Bu kapsamda, özkaynak artırmak veya azaltmak amaciyla işletmelerin yaptıkları harcamalar, gelecekte işletmeye herhangi bir varlık sağlamayacak olması ve tek başına ticari ilişkiye konu olabilme özelliğinin olmamasından dolayı maddi olmayan duran varlık olarak sınıflandırılmayacaktır. 


\subsection{Muhasebe Standartlarındaki İlgili Düzenleme}

TMS 38 Maddi Olmayan Duran Varlıklar Standardı'na (TMS 38, ) göre, herhangi bir varlığın maddi olmayan duran varlık olarak sınıflandırılabilmesi için aşağıdaki hususları taşıması gerekmektedir.

1- Gelecekte işletmeye ekonomik yarar sağlama,

2- $\quad$ Belirlenebilirlik (ayrılabilir olması, işletmeden ayrılabilme ya da bölünebilme özeliğine sahip ve bireysel olarak ya da sözleşme satılabilir özelliği),

3- Kontrol edilebilirlik (işletmenin ilgili varlıktan ortaya çıkan ekonomik yararları kullanabilme ve başkalarının bu yararlara erişimini kısıtlama gücü),

TMS 32: Finansal Araçlar Sunum Standardı'nın (TMS 32) 37. Maddesine göre, "İşletme özkaynağına dayalı finansal araç ihraç etmesi ya da anılan aracı geri satın alması sırasında çeşitli maliyetlere katlanır. Bu maliyetler, tescil ve diğer mevzuata dayalı olan ücretler, yasal, mali ve diğer profesyonel danışmanlık ücretleri, basım maliyetleri ve damga vergilerini kapsar. artırım işleminde, doğrudan işlemine atfedilebilen, katlanılmasına gerek olmayan ek harcamalar olması durumunda, ilgili harcamalar tan indirilerek muhasebeleştirilirler. Bunun yanı sıra, vazgeçilen işlemleri ile ilgili harcamalar gider olarak muhasebeleştirilir." Buna göre, işletmenin sağlamak veya azaltmak amacıyla yaptığ1 harcamalar kontrol ve gelecekte işletmeye ekonomik yarar sağlayamaması ilkelerini sağlayamadıklarından bu işlemlere yönelik yapılan harcamalar aktifleştirilmeyip, tan indirilerek muhasebeleştirilecektir.

TMS 32'nin 38. maddesine göre işletmenin, birden fazla işlemle ilgili işlem maliyetleri (örneğin bazı hisse senetlerinin arz edilmesi işlemleri ile diğer bazı hisselerin borsaya kaydedilmesi işlemlerinin eş zamanlı olarak gerçekleştirilmesi ile ilgili maliyetler), makul ve benzer işlemlerle tutarlık arz eden bir tahsis yöntemi esas alınmak suretiyle ilgili işlemlere dağıtılması gerekir. Çok sayıda işleme ait maliyetlerin uygun dağıtım yöntemi yolluyla işlemlere dağıtılması gereklidir.

\subsection{Vergi Mevzuatındaki İlgili Düzenlemeler}

Vergi mevzuatında, kuruluş örgütlenme ve sermaye artırım işlemleriyle ilgili 5520 Sayılı Kurumlar Vergisi Kanunu’nda (KVK) ve 213 Sayılı Vergi Usul Kanunu’nda(VUK) düzenlemeler yapılmıştır. KVK hangi giderin matrahtan indirilebileceğini belirlerken, VUK ise, ilk muhasebeleştirme ve dönem sonu değerleme ile ilgili hükümleri belirlemektedir.

5520 sayılı KVK’nın 6. maddesine göre, “Kurumlar vergisi, mükelleflerin bir hesap dönemi içinde elde ettikleri safi kurum kazancı üzerinden hesaplanır. Yine aynı maddede, safi kurum kazancının tespitinde, ayrıca 193 Sayılı Gelir Vergisi Kanunu'nun (GVK) ticarî kazanç hakkındaki hükümleri de uygulanır.” denmektedir. Bu kapsamda, safi kurum kazancının tespitinde, hem 193 sayılı GVK'da hem de 5520 sayılı KVK’da düzenlenen giderler dikkate alınacaktır. GVK'da safi kazancının tespitinde indirilebilecek giderler 
GVK'nın 40. maddesinde düzenlenmiş olup bu giderler arasında kuruluş ve örgütlenme ve menkul kıymet ihraç giderleri sayılmamıştır. Ancak, KVK 8. Maddesinde safi kazancın tespitinde hükmün a fikrasında menkul kıymet ihraç giderlerini, b fikrasında da kuruluş ve örgütlenme giderleri sayılmıştır. Daha sonra 03/04/2007 tarih 26482 Sayılı Resmi Gazete’de yayınlanan 1 Seri Kurumlar Vergisi Genel Tebliği'nde menkul kıymet ihraç ile kuruluş ve örgütlenme bazı gider çeşitleri ayrıntılı bir şekilde açıklanmıştır. Söz konusu tebliğe göre;

Menkul kıymet ihraç gideri olarak; senetlerin kağıt ve basım giderlerini, mahkeme, noter ve diğer tasdik ve tescil giderlerini, damga vergisini ve ihraç dolayısıyla ödenen sair harç ve resimleri, ihraç dolayısıyla bankalara verilen komisyonları, hisse ve tahvil senetlerinin borsaya kaydı için yapılan giderleri ve bunlara benzer diğer her türlü giderleri saymak mümkündür.

Kuruluş ve örgütlenme giderleri olarak; kurumların kuruluşları sırasında yapılan; ana sözleşmenin hazırlanması, kuruluş genel kurul toplantılarının yapılması, tanıtma ve reklam gibi kuruluş ve örgütlenmeye ilişkin bir takım giderleri bunlara benzer diğer her türlü gider olarak ifade edilmiştir.

VUK’un 282. maddesinde kuruluş ve örgütlenme giderlerini, "kurumun tesis olunması veya yeni bir şubenin açılması veyahut da işlerin devamlı surette genişletilmesi için yapılan ve karşılığında maddi bir kıymet iktisap olunmayan giderler” olarak açıklanmıştır. Söz konusu maddede Kuruluş ve örgütlenme giderlerinin ilk defa muhasebeleştirilmesine ve dönem sonundaki değerlemesine ilişkin hükümleri düzenlemiştir. Yine bu maddeye göre, kuruluş veya işletme bünyesinin genişletilmesine özgü giderler bir defada gider yazılabileceği gibi aktifleştirilerek amortisman yoluyla da giderleştirilebilmektedir. Mükelleflerin bu konuda tercih hakkı bulunmaktadır.

\subsection{Diğer Mevzuatta Yapılan Düzenlemeler}

1 Sıra No’lu Muhasebe Uygulamaları Genel Tebliğine göre, işletmelerin kurulması, yeni bir şubenin açılması, işlerin sürekli olarak genişletilmesi için yapılan ve karşılığında maddi bir değer elde edilmeyen giderlerin aktifleştirilmeleri durumunda; "262.Kuruluş Ve Örgütlenme Giderleri” hesabına alınarak, maddi olmayan duran varlık olarak sınıflandırılacaktır. Öte yandan, yapılan harcamalar gider olarak sonuç hesaplarına alınması durumunda “653 Komisyon Giderleri” hesabına alınıp, ilgili tutar gelir tablosunda raporlanacaktır.

\section{SERMAYE ARTIRIM IŞLEMLERINIIN MUHASEBELEŞTİIILMESİ}

Bu çalışmanın kapsadığı asıl araştırma alanını dikkate alarak, konunun daha iyi anlaşılabilmesine yönelik olarak aşağıdaki muhasebe örneği verilmiştir. Söz konu örnek, TMS, 6102 Sayılı TTK, 5520 Sayılı KVK ve 213 Sayılı VUK’un ilgili hükümleri dikkate alınarak hazırlanmıştır. 
Örnek Olay ${ }^{1}$ : A işletmesi önceki y1llarda 250.000 adet hisse senedini halka arz etmiştir. 1 Ocak 2014 tarihinde ise 500.000 adet daha hisse senedi arz etmiştir. Hisse senetlerini halka arz etmek konsorsiyum şirketine 350.000- TL ödeme yapılmış, Yeni ihraç edilen ve mevcut hisse senetlerinin y1llk Borsa İstanbul kotasyon aidatı olarak 300.000- TL ödenmiş, mevcut ve yeni ihraç edilen hisse senetlerinin izahname tasarım baskı ve hukuki danışmanlık ücreti olarak 450.000- TL'lik ödeme yapılmıştır.

Yukarıdaki örnek olaydaki giderler, muhasebe kavramlarına (dönemsellik) ve aşağıda verilen açılamalara göre muhasebeleştirilecektir.

Yeni hisse senedi ihraç edilmesiyle, doğrudan bağlantısı olan giderler, hisse senedinin ihracı sonucu elde edilen tutarından indirilecektir (TMS-32, Md. 37 ve 38.).

- $\quad$ Yeni hisse senedi ihracı ile doğrudan ilişkisi olmayan giderler, gelir tablosunda gider olarak yanstitlacaktır(TMS-32, Md. 38).

- $\quad$ Yeni hisse senedi ihracına yönelik ve kotasyon iznine ilişkin ortak giderler, makul ve tutarlı bir yönteme göre paylaştırılacaktır (TMS-32, Md. 38)

Hisse senetlerini halka arz etmek konsorsiyum şirketine yapılan ödeme doğrudan ve sadece halka arz süreciyle ilgili olduğu için 350.000- TL tutar tutarından indirim olarak kabul edilmesi gerekir.

Yeni ihraç edilen ve mevcut hisse senetlerinin yıllık Borsa İstanbul kotasyon aidatının dönemsellik kavramı gereği, 2014 yıllının gideri olarak kabul edilmesi gereklidir. 300.000TL’lik giderin 180. Gelecek Aylara ait Giderler Hesabına Aktarılması gereklidir.

Mevcut ve yeni ihraç edilen hisse senetlerinin izahname tasarım baskı ve hukuki danışmanlık ücreti olarak ödenen 450.000- TL’lik ödemenin bir kısmı, yeni hisse senetleri dolayısıyla oluşan yıllık olarak ödenmeyen giderlerdir. Bu sebeple, uygun dağııım anahtarla bir kısmının 2014 yıllına ait gider olarak, bir kısmının ise özkaynakden indirilecek şekilde dağıtılması gereklidir (mevcut ve yeni hisse senetleriyle ilgili olan giderler hisse senetleri sayısıyla orantılı olduğu varsayılmıştır). Ortak giderler aşağıdaki yönteme göre yapılmıştır.

$$
\text { Özsermayeden İndirilecek Tutar }=\frac{\text { Yeni İhraç Edilen Hisse Senedi }}{\text { Toplam Hisse Senedi }} \times \text { Toplam Maliyet }
$$

\footnotetext{
${ }^{1}$ Halit, Aykut, (2014), UFRS Gündeminden Seçmeler, İlk Halka Arz’a İlişkin Giderler adlı eserinden uyarlanmıştır.
} 
Hisse Senedi

İhracına İlişkin Pay

$=(500.000$ Adet $/ 750.000$ Adet $) \times 450.000-\mathrm{TL}=300.000-\mathrm{TL}$

Kotasyona İlişkin Pay

(250.000 Adet/750.000 Adet )x 450.000- TL $=150.000-\mathrm{TL}$

$\mid$

500 SERMAYE
Kotasyon Giderleri
İzahname ve Hukuki Giderler Payı
GELECEK AYLARA AİT GİDERLER
Kotasyon Giderleri
İzahname ve Hukuki Giderler Payı
102 BANKALAR
X bank
İşletmenin yeni hisse senedi ihraç giderleri ve borsa
kotasyon ücretlerinin muhasebeleştirilmesi.

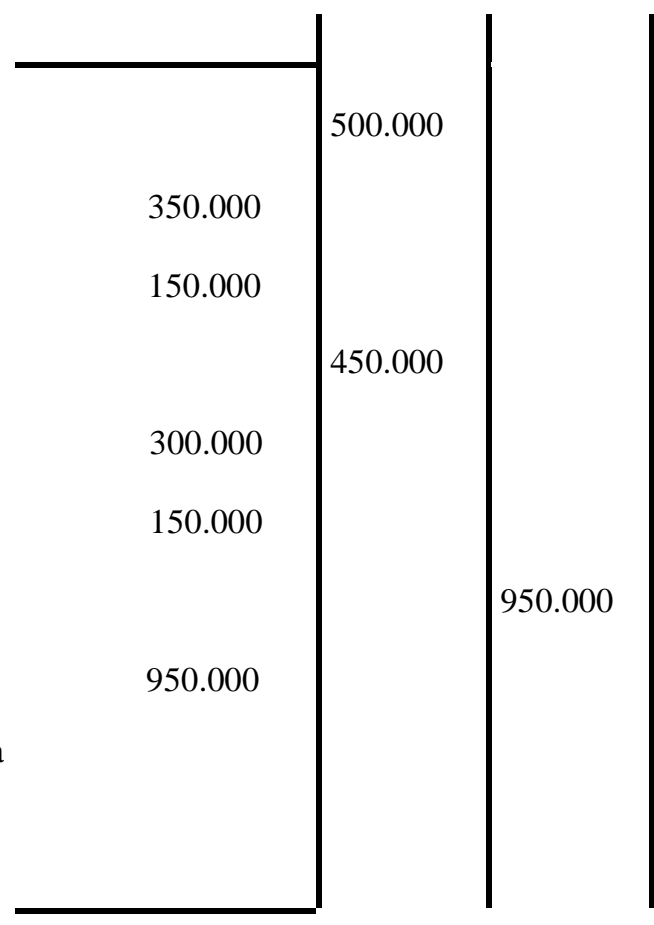

Daha önce açıklandığı üzere, 5520 Sayılı KVK’nın 8. Maddesinin a fikrasında menkul kıymet ihracına yönelik olarak yapılan giderleri matrahtan indirmeye izin vermekteydi. 213 Sayılı VUK'da giderin aktifleştirilmesine veya giderleştirilmesine izin verdiğinden dolayı, menkul kıymet ihracına yönelik yapılan giderler için aşağıdaki nazım hesapta vergi düzeltme kaydı yapılmıştır.

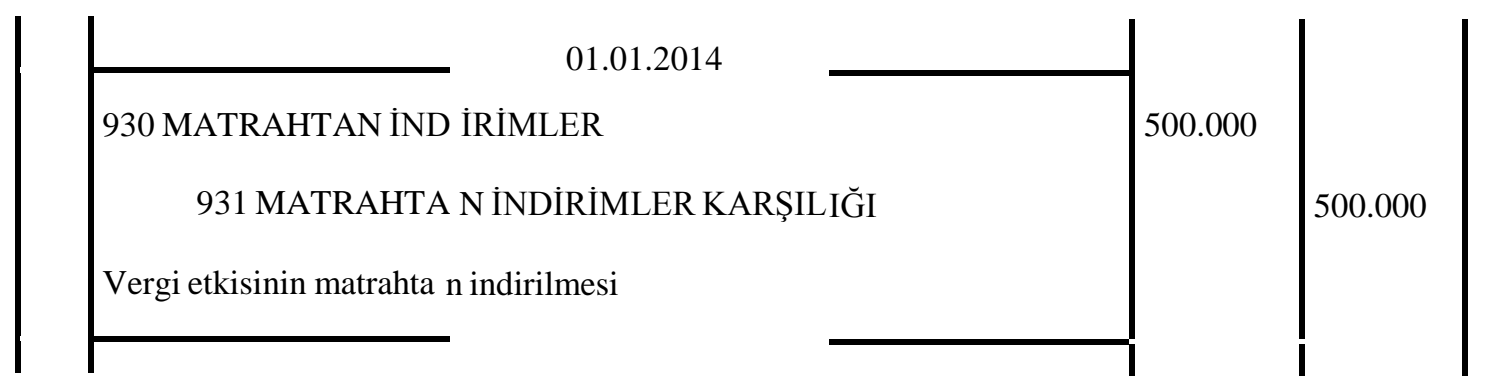




\section{SONUÇ}

6102 sayılı yeni Türk Ticaret Kanunu’nda esas sermaye sistemi yanında kayıtlı sermaye sistemine yer verilmiştir. Sermaye artırımı "sermaye taahhüdü yoluyla sermaye artırımı, iç kaynaklardan sermaye artırımı ve şarta bağlı sermaye artırımı" olmak üzere üç başlık altında düzenlenmiştir. Sermaye artırımına, esas sermaye sisteminde genel kurul; kayıtlı sermaye sisteminde ise yönetim kurulu karar vermektedir.

Türkiye’de VUK, TTK, Muhasebe Standartları muhasebe uygulamalarına yön veren düzenlemelerdir. Sermaye artırım işlemlerinde farklı düzenlemelerin olması sebebiyle, muhasebe sonuçlarının da farklı olmasına neden olmaktadır. Söz konusu düzenlemeler nedeniyle muhasebe sonuçlarının farklılık göstermesine neden olmaktadır.

Sermaye artırım işlem maliyetlerinin muhasebeleştirilmesine yönelik TTK, TMS, KVK ve VUK'da düzenlemeler ihdas edilmiştir. Buna göre, TTK’da Türkiye Muhasebe Standartları'nda aksi öngörülmemişse; işletmelerin özkaynak edinmelerine ilişkin olarak yaptıkları harcamaların giderleştirilmesini öngörmektedir. TMS 32'de, özkaynaknin artırılmasıyla doğrudan bağlantısı bulunan giderlerin özkaynakden indirilmesine izin verilirken, KVK'da Menkul kıymet ihraç ile kuruluş ve örgütlenme giderlerinin matrahtan indirilmesine izin vermektedir. VUK'da ise, özkaynaknin artırımına yönelik yapılan harcamalar için hem aktifleştirmeye hem de giderleştirilmeye izin verilmektedir.

\section{KAYNAKLAR}

Başaran, Funda (1999), Alman ve Türk Vergi bilançosu Hukukunda Gayri Maddi İktisadi Kıymetleri Aktifleştirme Şartları, Beta Yayınevi, İstanbul

Collin, S.M.H. (2007), Dictionary of Accounting, Fourth Edition, A \& C Black Publishers Ltd, London

Halit, Aykut, (2014), “UFRS Gündeminden Seçmeler, İlk Halka Arz’a İlişskin Giderler” http://www.gtturkey.com/UD_OBJS/PDF/UFRS_GUNDEM/UFRS_KONULARI_1_MAKA LE.pdf , ( 20.11.2014)

İnal, Nihat (2003), Adli Tıp ve Ekonomik Terimli Hukuk Sözlüğü, Özel basım / Sözkesen Matbaacılik, Ankara

Parasız, İlker (2007), Modern Ansiklopedik Ekonomi Sözlüğü, Ezgi Kitabevi, Bursa

Şengür, Evren Dilek (2011), "Yeni Türk Ticaret Kanunu İle Anonim Şirketlerde Sermaye İle İlgili Getirilen Yenilikler”, Mali Çözüm, Ocak Şubat, ss. 97-120 
Yavuz, Mustafa (2011), “Yeni Türk Ticaret Kanunu’na Göre Anonim Şirketlerde Sermaye Artırım Usulü”, e-yaklaşım, Kasım 2011, Sayı 227

Türkiye Muhasebe Standardı 32: Finansal Araçların Sunumu, 28/10/2006 Tarih ve 26330 Sayılı Resmi Gazete

1 Sıra No’lu Muhasebe Uygulamaları Genel Tebliği, 26/12/1992 tarihli ve 21447 Resmi Gazete

6102 Sayılı Türk Ticaret Kanunu, 13/01/2011 Tarih ve 27846 Sayılı Resmi Gazete

6762 Sayılı Türk Ticaret Kanunu, 09/07/1956 Tarih ve 9353 Sayılı Resmi Gazete

1 Seri No’lu Kurumlar Vergisi Genel Tebliği , 03.04.2007 tarih 26482 Sayılı Resmi Gazete

5520 Sayılı Kurumlar Vergisi Kanunu, 21/06/ 2006 Tarih 26205 Sayılı Resmi Gazete

193 Sayılı Gelir Vergisi Kanunu, 6/01/1961 Tarih 10700 sayılı Resmi Gazete

213 Sayılı Vergi Usul Kanunu, 10.01.1961 tarih ve 10705 sayılı Resmi Gazete 